\title{
Effects of Food Processing on the Stability and Quality of Shellfish Allergens
}

\author{
ALsailawi Hasan Ali and M. Rosmilah \\ Department of Biology, Faculty of Science and Mathematics, University Pendidikan Sultan Idris, Tanjong Malim 35900, Perak, \\ Malaysia
}

\begin{abstract}
The high number of allergens that exist in the human food supply had led to increment of food allergies awareness by taking suitable prevention to protect sensitive consumers from unsolicited exposures to food allergens. Several attempts were done to lessen or eradicate the food allergenicity via food processing which eventually resulted in mixed outcomes. The rationale behind the usage of food processing to reduce/remove the food allergenicity and the limitations encountered are further discussed.
\end{abstract}

Key words: Food allergy, processing, stability, shellfish allergy.

\section{Introduction}

\subsection{Food Allergy}

Food allergy is an IgE-mediated abnormal that reacts to food protein tolerant. However, the reasons behind the issue of intolerant towards certain food protein are vague. For instance, an individual requires a certain amount of protein such as the threshold, which remains unknown, in order for the allergic response to happen in a sensitized person who can be from patient to patients and protein to protein. Besides that, a food allergy can also be in the form of severe anaphylaxis, which can cause death. Range of food allergy symptoms can be in the form of flushing, urticaria, angioedema, laryngoedema, diarrhea, nausea/vomiting, bronchospasm, or hypotension. Therefore, the best way to avoid accidental exposure to food allergens is to avoid consuming the offending food. Though avoidance can be impossible, yet in certain cases, it can be avoidable. As for the food labelling, it is crucial for the manufacturers to have accurate food labelling to improve the consumers' safety and help the food producers, manufacturers, distributors, packers, transporters, and retailers to ensure that the ingredients

Corresponding author: ALsailawi Hasan Ali, PHD are efficient and safe. However, though many plans and practices had been conducted, the existence of trace contamination of offending agent cannot be determined unless there is an accurate procedure to discover their existence. Due to this matter, a reliable, robust, specific, and accurate method should be developed to discover the trace quantities of food allergens.

Allergy is an inappropriate immune response to an allergen. An "allergen" is the substances to which the allergic individual is sensitized and reacts [1]. Allergens have the ability to sensitize a hypersensitive individual by triggering the production of specific IgE antibodies, the ability to the IgE antibodies and the ability to cause an allergic reaction [2]. Allergens are generally proteins with a size of 10 and $60 \mathrm{kDa}[1,3]$. However, the whole allergen is not involved in the immune response; only its specific binding site, called as epitopes have ability to bind to $\operatorname{IgE}$ antibodies and contribute to allergic reactions [4].

Allergen is classified as the major or minor allergens. An allergen is considered major when $\operatorname{IgE}$ antibodies of at least $50 \%$ of the allergic [1], recognize the allergen. Understanding the structure and function of major allergens is important to understand the $\operatorname{IgE}$ reactivity in patients, the mechanism of allergy and to the development of sensitive and improved diagnostic 
approaches [5]. Meanwhile, minor allergen is recognized by less than $50 \%$ of the allergic population [1]. Minor allergens may contain certain structure similarities as major allergens that allow for IgE-binding but do not have the conformation necessary to elicit allergic reactions [6].

To date, several major allergens have been successfully recognized in shellfish including crab including tropomyosin [7-11], arginine kinase [12-14] sarcoplasmic calcium-binding protein $(20 \mathrm{kDa})$, troponin (23 kDa), $\alpha$-active (42 $\mathrm{kDa})$, smooth endoplasmic reticulum $\mathrm{Ca}^{2+}$ ATPase $(113 \mathrm{kDa})[9]$ and myosin light chains [15].

\subsection{Shellfish Allergy}

Crustacean allergies occurred due to the presence of allergens in the crustacean. The IgE-mediated shellfish allergies can lead to severe reactions $[16,17]$. Due to its availability throughout the world, the allergy source from the crustacean shellfish allergy is rapidly spreading to various areas. Besides, the allergies from the molluscan shellfish are also another contributor of seafood allergies. However, they are not frequently reported and they do not appear as often as the crustaceans [18]. According to $\mathrm{Lu}$ et al. [19], an IgE-mediated or known to be type I allergy is a type of allergy that originated from the crustacean allergy. Additionally, other crustacean shellfish such as shrimp and prawn were claimed to be as a good source of nutritional seafood. Unfortunately, they are also the major contributor to the allergy throughout the world.

In Southeast Asia, crabs have been highly demanded due to the claim that they have large chelae and higher meat content. Thus, among crustaceans, crabs are the frequent causes of shellfish allergy in several countries. The Food and Agriculture Organization (FAO), as well as the World Health Organization (WHO), highlighted that crab and shrimp are the common sources of food allergens as their allergic reactions can be induced by ingestion [20].

\section{Effects of Processing on Allergen Stability}

Foods may undergo various processing methods for the purpose of preservation from microbes, modification of texture, taste or colour and the improvement of digestibility [21]. In majority of the cases, thermal processing techniques such as steaming, boiling, roasting, or frying are commonly used [22]. In addition, the applications of non-thermal treatments such as drying, acid hydrolysis and salting are widely increasing due to the benefits of minimal effect on nutritional and qualities of foods [23].

Heat treatment had been practiced for food processing since ancient times. The purpose of thermal treatments is to preserve the quality of the food to ensure that the food is being stored safely and to modify its features such as by obtaining new textures and flavours [24]. Heat treatments can lead to various changes in the lipids and carbohydrates such as aggregation by non-covalent, denaturation, disulphide bond reaction, and hydrolysis of peptide bonds in the food molecules.

However, when the food was being heated, the components in the foods had experienced a transformation, which directly affects the level of the allergenicity in the food. Past studies highlighted the modification of the food allergenicity based on the heat treatment process and Maillard reaction. The result of these reactions had proven that thermal processing has an influential impact on the proteins' allergenicity whether it can be reduced by reducing the epitopes or enhanced by exposing the epitopes [25].

In terms of the change in the proteins structure, factors such as the form of protein and the thermal load contribute to the changes. For example, when whey proteins were heated up, its structure denatures gradually [26]. Meanwhile, the caseins are claimed to be heat stable because they do no longer possess any level of structures that can be disturbed when it is being heated. This indicated that the process of heating milk could partly be considered as effective to reduce its allergenicity [27, 28]. 
In milk, studies reported that sterilization at high temperature at $90-95{ }^{\circ} \mathrm{C}$ leads $75 \%$ of denaturation of the whey proteins $[26,29]$. Additionally, it also causes the denaturation and aggregation of $\beta$-lacto globulin, which significantly reduced the whey proteins' IgE-binding capability [30, 31]. Their research highlighted that heating food such as milk became inadequate to eliminate or damage all epitopes. However, the residual epitopes can be lower or it may additionally be destroyed after heating. Similarly, Bu et al. [32] had conducted a study on the impact of the Maillard response of $\alpha$-lactalbumin onto IgG-binding. The outcome revealed that the conjugation of $\alpha$-lactalbumin with less sugar helped to decrease the whey proteins' IgG-binding ability. In contrast, Taheri-Kafrani et al. [30] discovered that conjugation of $\beta$-lactoglobulin with lactose (reducing sugar) can cause the reduction of the $\mathrm{IgE}$ recognition. However, according to Maynard et al. [33], the heating may additionally revealed that inside $\alpha$-lactalbumin is a hidden IgE-binding epitope.

Another example of heat-sensitive allergens was studied extensively in egg [34]. In vitro research had been conducted to assess the IgE-binding potential to show that the heating of ovalbumin can lessen the IgE-binding potential as to the unheated ovalbumin [35, 36]. Additionally, the heat treatment of an ovomucoid also reduced the activity of the IgE-binding of an ovomucoid. However, using the Maillard reaction for glycation may increase the bindings of the IgE [24]. Other heat-labile proteins are ovotransferrin and lysozyme and they showed a decrease in IgE-binding after being heated for 15 minutes at the temperature of $95{ }^{\circ} \mathrm{C}[37]$.

Thermal processing has been also comprehensively studied on its impact as many had claimed that thermal processing is effective in reducing the reaction of IgE-binding in several other allergens. Allergens such as Mal $\mathrm{d} 1$ from apples, Api g 1 from celery, and Cor a 1.04 from hazelnuts [38] were exposed to be heat-sensitive. Thermal processing such as roasting may cause some to lose their allergenicity. Jeebhay et al. [39] mentioned that the reduction of allergenicity happened due to the alteration of the conformation from the heat liable protein when they are exposed to the heat, which then caused the loss of epitopes.

However, various food allergens are claimed to be heat resistant such as Pru $\mathrm{p} 1$ from peaches and Ara h 1 from peanuts. Besides that, fish allergens have also been reported to be heat resistant. For instance, parvalbumin is a major allergen in whiff, which is highly resistant protein [40]. Furthermore, it was highlighted that the extract from the whiff tended to be bigger in number of $\mathrm{IgE}$ reactive band and displayed greater resistance to the pepsinolysis than the raw samples. The heating may influence the formation of aggregates, which then expound the incremented allergenicity of cooked whiff. Besides parvalbumin, Gad c 1 in cod also claimed to be heat resistant. The transmutations in the matrix aliment affect the heat on allergens, which then varies in the fish species [41]. Boye [42] highlighted that the highest allergenicity of bhetki happened to be discovered in the fried extract. The incremented allergenicity of fried bhetki initiated from the exposure of the incipient epitopes or the reaction of Maillard. In peanuts, the Ara h 1 and Ara h 2 have higher IgE and more resilient to the heat and digestion after undergoing the Maillard reaction.

Meanwhile, tropomyosin, the major shellfish allergens including crabs, have also been reported as a highly thermo stable food allergen [43]. Based on the secondary structure of the stable alpha helical coiled-coil, the tropomyosin has the tendency to resist the heat-treatment and various form of kenned victuals processing techniques. However, there are still inadequate amounts of information on the impact of heat processing for diagnosing the tropomyosin from other shellfish groups. Additionally, the molecular distinctions between tropomyosin and other shellfish groups should be noted as changes happened after undergoing the heating process [44].

Researches on various cooking methods were 
conducted to discover the impacts of the methods onto the cockle's allergenicity and to diagnose the type of proteins that commonly attached the IgE antibodies through proteomics approach. When the extracts were heated, the number of IgE-reactive bands decreases. This had shown that the smaller number of protein bands and IgE-reactive bands were found when the extracts were boiled, fried, and roasted. In the demonstration order of raw $>$ boiled $>$ fried $\approx$ roasted, the degree of cockle's allergenicity was discovered. The immunobloting of the raw extract showed 11 IgE-binding proteins with two major allergens at 36 and $48 \mathrm{kDa}$, while the boiled extract showed only 3 IgE-binding proteins. As for the fried and roasted extracts, there was only a single IgE-binding protein at $36 \mathrm{kDa}$, identified as tropomyosin [45].

As most allergens are mainly proteins, the heat treatment methods may result in the modification of allergenicity, which may change their structure. When the protein structures are altered, it can lead to epitope changes, masking and unmasking the structure, which can eventually lead to the decrement, increment, or no impact on the allergenicity [46]. Shellfish such as crabs are customarily associated to the various ways of heat treatment such as boiling, frying, or roasting before being consumed [8]. However, it was noticeable that there is scarcity in the information related to the heat sensitivity or heat resistant of crab allergens. Thus, it is crucial to have studies that can investigate the impact of various cooking methods to the allergens [47].

\subsection{Thermal Processing}

\subsubsection{Moist Heat}

(1) Boiling

Boiling is one of the most common cooking methods which involve the prompt vaporization of a liquid when it is being heated up to its boiling point and the temperature at the vapor pressure is equal to the pressure applied by the surrounding to the liquid. In order to kill the microbes, boiling water is selected as the appropriate method to be conducted. Different organisms have different level of heat sensitivity. For instance, many organisms will be killed if the water is at $70^{\circ} \mathrm{C}\left(158^{\circ} \mathrm{F}\right)$ for 10 minutes. However, there will be some other organisms that can withstand the heat and may even require additional minute at to reach the boiling point of water. Boiling is considered to be an appropriate method for large-scale cooking [48].

A study on shrimp reported that the extract from the boiled shrimp has less IgE-binding protein than the extracts from raw shrimp. It was mentioned that the boiling might cause alteration to the shrimp extracts, which allows the allergenic epitopes to reduce the allergen recognition. Therefore, to alter the allergenicity of the food, boiling has been suggested to be the procedure to eradicate the allergens. The outcome revealed that the stability of the thermal in the purified tropomyosin (TM) from boiled shrimp was similar to the purified TM from a raw shrimp. In addition, it was observed that the activity of the IgE-binding of a boiled TM was stronger than to the raw TM. This is because the boiled TM may have gone through the process of protein-protein exchanges, which allows the aggregation to happen during thermal treatment. This happened to enhance the IgE binding reactivity and the activity of unmasking the $\operatorname{IgE}$ epitopes to have accessible surfaces. Generally, the application of boiled TM is more effective when diagnosing seafood allergy including crabs [49].

(2) Frying

Frying is the type of cooking that involves the usage of oil. Food such as the chips, eggs and egg-based food such as omelets or pancakes are normally being produced by frying. Generally, fats and oils can have higher temperature than water at normal atmospheric pressure. Thus, food will be cooked faster with extra features of crispness in the texture. The penetration of the fat depends on the type of food to varying degrees, which may contribute to the lubricity, flavours, as well as calories. There are various factors that lead to the variety of frying techniques such as the cooking time, the type of cooking vessel required, and the amount of 
fat needed. Among the standard frying, techniques are deep-frying, shallow frying, stir-frying, and sauteing [50].

A study revealed that both frying and roasting of cockle have modified the proteins in a similar way. According to Zailatul et al. [51], most of the fried sample's protein bands had been eliminated as compared to the raw and boiled cockle. Another study, which was performed on Bombay locust, identified that after the frying process, the allergenicity of arginine kinase and enolase in Bombay locust was decreased, while glyceraldehyde-3-phosphate dehydrogenase was increased. The study concluded that thermal processing treatment of frying process might give alteration in a structural way and may modify the allergenicity of Bombay locust by abolishing existing protein epitopes to reduce allergenicity or may create new epitopes to increase allergenicity [52].

(3) High Pressure Processing (HPP)

In seafood product, high pressure processing (HPP) has been applied to inactivate the microorganism and enzyme, which has less impact on the colour, flavours, and the nutritional value of the food. Furthermore, HPP has led to significant changes in the protein such as partial protein unfolding the covalent and non-covalent interactions during the pressurization and after releasing the pressure. Due to this partial denaturation of proteins, several functional properties were being modified. These modifications resulted to significant positive changes in the texture of the products [53]. Additionally, the differences in the texture can be compared between the proteins that were eradicated or damaged due to less allergen content, which had been structurally modified [54].

\subsubsection{Dry Heat}

(1) Roasting

Roasting is a cooking method that applies dry heat process in which the hot air surrounds the food and cooks the food evenly all rounded with the temperature of $150^{\circ} \mathrm{C}$. Roasting can be conducted in an open flame, oven, or other heating appliances. It was mentioned that roasting helps to improve the flavours as well as the texture of the food, which can create Maillard browning on the food's surface. Generally, roasting is done using indirect, diffused heat, which is appropriate to cook in larger amount or bigger piece of meat. However, it normally takes approximately 1-3 hours to cook which eventually resulted to tendered cooked meat [55].

A study on food allergens, such as peanuts which often are handled through the roasting process, indicated that the method had managed to alter the 3D structure of the allergens and cause Maillard modification [56]. Comparison between roasted peanuts and fried peanuts was done to discover that the amount of Ara $\mathrm{h} 1$ was reduced in fried peanuts. This is because the roasting process does not affect the $\operatorname{IgE}$ binding to Ara h 1. Additionally, the efficiency of Ara h 1 extraction and the accessibility of the epitopes are obtained from the process of roasting which can be determined based on the antibodies that measure the allergen [57].

\section{(2) Microwave Heating}

Presently, the use of microwave for heating has been increasing as it brings many advantages such as in-depth heating can be done without the temperature gradient, it allows higher heating rates and the timing can be reduced, prevent vitamins, flavours, and other water-soluble components to be leaking, and it activates the inactivation of enzyme complexes [58]. Additionally, the use of microwave energy is efficient as it has taken over the conventional methods. This has caught the attention of many researchers to study its application in various fields such as the advantages of microwave energy lead to the less energy consumption, its processing time as well as its impact on the environmental remediation. According to Jones [59], microwave heating overtaken the conventional methods due to its advancements such as higher heating rates, no direct contact between the food and the heat, and manageable control of the drying and heating process. 
Bohr and Bohr [60] asserted that the conformational changes of proteins and acceleration of the denatured process were caused by the use of microwave. This is because the changes in the protein's natural structure may affect their sensitizing properties. According to Venkatachalam et al. [61], some efforts were done to reduce the food allergens' immunoreactivity by using the microwaves as the technological tool.

However, some researchers highlighted that the usage of microwave heating is not enough to lessen the proteins' antigenicity and was recommended that it should be combined with other processes such as enzymatic hydrolysis for a better and effective outcome [62]. Izquierdo et al. [63] observed that during the combination of microwave heating process and pronase, papain or alcalase, there was a decrease in the immunoreactivity. Venkatachalam et al. (2008) tested the implication of microwave heating onto the almond allergens. They discovered that the IgE binding was not significantly affected in most conditions. However, at about 3 minutes under extreme microwave heat, the reduction of the IgE binding was noticed. Leszezynska et al. [64] highlighted that the reactivity of the IgE will increase if the material is exposed to the microwave at $40 \mathrm{~kg}$. Contrariwise, the more intense the energy of the microwave doses, the higher the IgE reactivity and the IgE binding levels can be compared to the untreated sample.

Other new technologies such as the used of high-pressure processing and food irradiation should be acknowledged in the heat treatment process. Furthermore, these new technologies are becoming more attractive to the food industry.

\subsection{Non-thermal Processing}

Non-thermal treatment is processing method that can inactive the microbial by not exposing the foods to heat with hostile effect. Furthermore, it extends the product's life by maintaining their physical, nutritional, and sensory qualities. In short, it is an alternative where no heat will be applied to the food sample. Non-thermal processing is a collection of technologies that can be used individually or in combination to enhance and improve the shelf life of fresh and refrigerated products [65]. Non-thermal processing method involves the process of acid processing, salting, enzymatic digestion, peeling, mashing, pasteurization treatment, and HPP.

Several researches on the effect of non-thermal treatments in altering allergenicity of food proteins showed that these treatments could lessen the allergenicity of different allergens in food [46].

\subsubsection{Salting}

Salt has the magnification of spoilage-causing microorganisms by taking out the hydrogen monoxide out of the tissue through osmosis. In this process, the sodium and chlorine ions develop a binding of hydrogen monoxide with complex reaction with protein that exerts by itself in an osmotic pressure. Finally, the balancing of the equilibrium and circumventing brine was attained [66]. Besides that, the outcome of the expected final product is the dependent to length of the salting period and the salt concentration. The acceptance of salt depends on various reasons such as its species, the fish size and its fillet's thickness, freezing, muscle type, weight, the composition of the lipid's content and distribution, physiological state, salting method, and brine concentration duration of salting step, fish-to-salt ratio, ambient temperature, and thawing. The purpose of the salt-boiled process for shrimp is to lessen the microorganisms load to enable it to amend the shrimp's flavours. Hence, a congruous salt-boiled muscle was significantly claimed to obtain the felicitous salt concentration to lessen the damage of the muscle and to preserve the red colour. Salted fish has the salt concentration that reaches $\approx 20 \%$. This is because in the process, high ionic vigor caused the myofibrils and dehydration of protein to contract [67].

The solubility of protein (or protein extractability) in salt solutions is one of the most important physicochemical properties in the manufacture of muscle food products. Protein solubility is often 
referred to as functional property or simply functionality. This characteristic is a result of comminuting and mixing of fish muscle tissue with salt. Protein extractability (solubility) is the percentage of total protein that enters the solution but does not sediment due to centrifugation. The breakage of proteins into smaller peptide units was caused by the high solubility of fish protein hydrolyses. This is because the solubility of the peptides has increased due to the lessening of molecular weight and increment number of polar groups available for hydrogen bonding with water dipoles. Furthermore, the equal amount of hydrophilic and hydrophobic elements in the peptides also contributed to the increment of their solubility [68]. Besides $\mathrm{NaCl}, \mathrm{pH}$ also affects the solubility of fish muscle proteins. Protein solubility profiles (i.e., curves) are typically determined to establish conditions required to solubilize fish muscle proteins. The selective protein solubility by shifting $\mathrm{pH}$ and salt concentration of the minced fish solution is a fundamental basis for the novel protein and lipid recovery technology taking advantage of isoelectric solubilization/precipitation [69].

In addition, the $\mathrm{pH}$ level and the type of salt to be used for the salting process can affect the degree of the protein denaturation. It was highlighted that up that between 8 and $20 \%$ was the content of the transmutation of protein in salted cuttlefish. After the slating process, the salt starts to correspond and the content of the crude protein started to be decremented which then lead to the loss of muscle protein into the extract. Meanwhile, electrophoresis was used to analyse the soluble muscle of the tissue protein of fish flesh. The outcome displayed that during the salting process, the amount of band had decreased. The electrophoretic studies revealed that the defragmentation in the number of the bands during the dry and wet salting process had slowed down the rate up to 9 hours. After 24 hours, the high-molecular weight proteins decremented more rapidly than the medium-molecular weight protein. This is because the medium molecular weight is more stable than the high-molecular weight protein [70].

So far, there is no literature that directly examines the effect of salting process (wet salting, dry salting) on the allergenicity of crabs.

\subsubsection{Drying}

Drying is an energy-efficient approach for the production convenient and delicious of rich protein product especially the aquatic products. Drying preserves the functional fractions or protein concentrations but lessens the purity. Globally, the annual production of dried aquatic products is about 350,000 tons and it continuously increases up to $7 \%$ in China every year and also in other Asian countries like Malaysia [71].

Two principal methods were introduced to preserve perishable foods, which are known as hot air drying (AD) and freeze-drying (FD). To compare the two, $\mathrm{AD}$ is a method that was considered to be more cost-effective than FD. However, the substantial quality of the food will be lost when undergoing the $\mathrm{AD}$ process, while the FD preserves the nutrients, flavours, colour, and the texture with minimal changes from the original products. Another technique is known as the heat pump drying (HPD). It is a drying technique that commonly is used to dry the heat-sensitive seafood which brings many advantages such as independent in controlling the operation parameters, low energy consumption, and less quality loss. In the flour production, these processes have been applied in the cereal technology to separate the endosperm and bran fraction by applying various techniques of milling and classification. The success of separating the pulses such as lentils, beans, and peas into protein-rich and protein-depleted fractions was mentioned in several studies by using the dry-fractionation [71].

To the best of our knowledge, scientific studies on the effect of the drying process on food allergenicity are not available in the literature. 


\subsubsection{Acid Processing}

Reducing the allergenicity of different kinds of food is best to undergo the process of acid processing as it was described to be successful and efficient. Martínez-Alvarez et al. [72] studied the impact of vinegar marinating onto the allergenicity of the shrimp allergens via the skin-prick test (SPT). The outcome revealed that they are able to obtain the diameters of the mean wheal by utilizing the extract from the shrimp which was prepared prior to the investigation by marinating it in vinegar. They discovered more minuscule than the mean wheal by using the extracts that were conventionally prepared. Meanwhile, Zheng et al. [73] highlighted that pickled-herring products such as rollmops and jellied-herring were prepared using acetic acid-salt brine to show the decremented IgE binding in three-fifth of the sera by using IgE predicated competitive ELISA. In general, the modification of the allergens' structure caused the vicissitude of allergenicity after undergoing the vinegar treatment [74].

At the acidic $\mathrm{pH}$ level, it was observed that there was a partial loss in the fish allergen, Lep w 1 structure and the degradation of proteolytic of the parvalbumin due to the acidic protease activity (cathepsin D). This is because the allergic reaction via the mechanism was lessened by the acid treatment, which transmutes and modifies the content and the structure of the allergens. Bessot et al. [75] asserted that vinegar has affected to the lentils and eggs as it reduces the $\mathrm{pH}$ value of the gastric, which eventually reduce the allergenicity and enhance the digestive system. Meanwhile, Suzuki et al. [76] chose the paramount of $\mathrm{pH}$ and its impact on the pabulum allergies as their focus of their study. They stated that the loss of pancreatic enzymes occurred when the gastric acid level determined the activation of the gastric pepsin. Thus, when the antacid drug prevents the gastric acid, there is a possibility that the allergic reaction will be increased drastically [77].

Vinegar at different $\mathrm{pH}$ and time of marinated impacted significantly onto the form of the marinated shrimp. Normally, the shrimp samples undergo an increment in their weight when they are marinated in the vinegar at the $\mathrm{pH}$ value of 1.0 and 2.5 after 3 hours. However, shrimps that are marinated in the vinegar at the $\mathrm{pH}$ value of 3.5 and 4.8 experienced negative mass reduction due to loss of moisture. This outcome supports the agreement regarding the impact of lactic and citric acid onto the tenderization of the beef. It has proven that the samples will attain higher moisture acceptance when the marinade is at highest acid concentration (lowest acidic $\mathrm{pH}$ value) [78].

So far, there is no literature that directly examines the effect of the acid hydrolysis process on the allergenicity of shellfish including crabs.

\subsubsection{Enzymatic Hydrolysis}

One function of the digestive tract is to change food into a substance that will not activate the immune system to launch an attack. When the food was taken, the immune system will alter the metabolism of the recognized food protein as harmful. The body will launch several methods to prevent the immune system from attack. First, stomach acid will denature the food proteins [79]. Although the food protein was denaturing, it will still be allergenic. Additionally, fixed structure or linear amino acid sequence of the protein is directed to human's IgE antibody for the denatured food protein to maintain its allergenicity. It was suggested that individuals with high allergen sensitivity in the gastrointestinal (GI) area must go through the process of degradation of GI in the tract to resist low $\mathrm{pH}$, bile salts, and proteolysis to allow the allergen proteins to attain the intestinal immune system [80].

The most effective step for making food proteins harmless is enzymatic degradation. It begins in the stomach, where the acidic environment favours the protein denaturation. Denaturation sets up the protein for the optimal break down by pepsin enzymes, a nonspecific protease that is active at $\mathrm{pH} 2$ [44]. The immune system in the gut is triggered by the size of 
the protein. The larger protein can set off the alarm for IgG antibody production while for the smaller proteins or fragments are able for immunity activation. Several types of research demonstrate that antibody production to that food protein increases when the protein digestion was compromised [81].

Protein degradation continues in the intestine that belongs to the activity of trypsin enzymes secreted by the pancreas. Trypsin is a digestive enzyme that hydrolyzes proteins in the small intestine [44]. Larger food protein fragments in the intestinal tract have the potential to become allergens [82]. Otherwise, many researchers indicate that pre-treatment of food proteins with protease enzymes shows less allergenic potential [83].

Food allergens are resistant to pepsin digestion as digestibility test was claimed to be the most suitable approach in diagnosing the level of allergenicity in the new proteins. Furthermore, under simulated gastric fluid (SGF) condition, the food allergens are more stable than the non-allergens. For instance, the allergens of peanut and milk are more stable in SGF compared to the non-allergenic proteins such as seed lipoxygenase and soybeans. Thus, it is crucial to differentiate the food allergens from non-allergens as the stability of the digestion process in depending on it. However, contradictory outcome was attained when the food allergens are not necessarily resistant to the digestion. Yagami et al. [84] discovered that most of the fruit allergens were decomposed after being under the SGF for 8 minutes. As for the matter of simulated intestinal fluid (SIF), allergens from banana, potato, peach, and melon were not fully degraded after going through the process of digestion for 16 hours [85].

Additionally, the TM of digestible mud crab major allergen under SGF and SIF showed that the TM was resistant to pepsin. This is because the sodium dodecyl sulfate polyacrylamide gel electrophoresis (SDS-PAGE) used the TM that had been purified and the Western blot with the myofibrillar proteins to show that the pattern of TM degradation under the
SGF and SIF conditions was not affected by the presence of other protein. Meanwhile, the ELISA results showed that the proteinase treatment is a successful method to reduce the binding of IgE of TM [80].

In vitro test was performed to investigate the stability of sarcoplasmic calcium binding protein (SCP) under the condition of simulated human gastrointestinal. The digestibility of purified SCP was analysed by the SDS-PAGE in SGF. It was discovered that the band with molecular mass of $22 \mathrm{kDa}$ gradually digested. After 1 minute, a major fragment of $16 \mathrm{kDa}$ was formed and smaller proteolytic fragments appeared after a long period of digestion time. In contrast, the digestibility of the SCP in SCF decreased as compared to the one in SGF. It was discovered at the range of $14.4 \mathrm{kDa}$ to $18.4 \mathrm{kDa}$, the pancreatic juice was formed to investigate the fragments and their weights after 15 minutes. At 4th hour, the SCP was spotted to be partly degraded. Thus, to examine the capabilities of the IgE-binding of SCP-derived digested fragments, the ELISA and the activity of the IgE-binding of SCP digested by the pepsin were observed. For an hour, the capability of the IgE-binding of SCP was significantly lessened. However, after 4 hours, the pancreatic juice digestion showed to have little impact on the SCP allergenicity. In general, the anaphylaxis will occur and the food allergen will maintain in its gastrointestinal-like digestion [86].

In another study, the impact of digestive stability and reactivity of TM from the S. paramamosain with different approaches was conducted using the in vitro simulated gastrointestinal digestion and immunoassay. The outcome revealed that the digestion of TM in the simulated gastric fluid tends to be faster when it is being boiled. Furthermore, the digestion of the SGF and SIF was observed with the assistance of combined ultrasound and boiling (CUB). Out of the three processing techniques, it was found that HPS is the most effective method to encourage the degradation of 
TM using digestive protease and lessen the IgE-binding of TM in the simulated gastrointestinal system [85].

According to a research done by Lee and Park [87], the whelk allergens were fully digested in the simulated gastrointestinal fluid. After undergoing the thermal treatment, the allergen remains the same. This had proven that there are certain crustaceans stable when being exposed to the heat. Meanwhile, Villamie and Jong [88] highlighted that in the food-processing methods, it was discovered that an effective processing and maintenance technology is the ultrasound as it provides good directivity and strong penetration. Li et al. [89] had adopted the method of ultrasonic treatment onto the shrimp's protein muscle and extract. The outcome revealed that high-intensity ultrasound might facilitate to lessen the allergic properties that present in the shrimp allergen, which may bring benefits to the ones with allergies.

In general, to establish sensible and appropriate processing methods to reduce or remove the stability and reactivity of the TM of crab, it is crucial to study the impact of different methods on the crab allergens. In this study, the method that is most effective in the degradation of TM will be conducted and the reduction of its IgE-binding reactivity in vitro simulated gastrointestinal digestion was implemented to examine the digestive stability of TM extracted from crab that had been treated by boiling, CUB, and HPS [85].

Studies to examine the effect of enzyme hydrolysis process on the allergenicity of shellfish including crabs are very limited and hardly found in literature. Therefore, the study on the impact of different processing methods on crab allergens digestion was conducted to establish proper processing methods to reduce or remove the stability and reactivity of crab allergens.

\subsubsection{Storage}

Freshness is one of the main aspects used to determine the quality of food products. Due to the increasing demands from the consumers for hygienic and quality of food products, the issue of the food quality has been a concern issue among the consumers [90]. The freshness of food product is usually classified depending on several aspects including the color, flavor, odor or texture that result from different spoilage processes [91]. Odour is commonly considered to become an important parameter for the determination of food freshness besides it can be easily determined by the consumers [92].

In order to preserve the food for a long-term, frozen storage is considered to be an effective and ideal way, which can last up to three months [93]. However, if poor freezing is being practiced, the quality of the food will be reduced due to the weakening of colour, flavour, and texture [94]. The deterioration happens due to the denaturation and aggregation of muscle proteins [91]. This has caught the attention of many researchers to investigate the connection between the temperature of the storage, time, and the changes of the food products' quality. However, Sotelo et al. [91] highlighted that most of the past studies had only focused on the temperature that was below $-30{ }^{\circ} \mathrm{C}$ only.

However, when storing the frozen food, it was recommended that the temperatures such be between $-18{ }^{\circ} \mathrm{C}$ and $-20{ }^{\circ} \mathrm{C}$. Therefore, it affected the foods' quality as it relies on the length of time that the foods were being placed under those conditions [95]. It was concluded that the storage time and temperature have major effect on the protein denaturation's degree. In reference to Burgard et al. [94], the differences in the protein were stated to be higher after storing it at the temperature of between -10 to $-20{ }^{\circ} \mathrm{C}$ as compared to when being stored at $-30{ }^{\circ} \mathrm{C}$. Meanwhile, Gandotra et al. [96] highlighted the implication of freezing and chilling towards the muscle of a fish. It was reported that at the temperature of $12 \pm 2{ }^{\circ} \mathrm{C}$, the freezing of the fish muscle might lead to low spoilage than chilling it at $4 \pm 1{ }^{\circ} \mathrm{C}$. In this study, the researcher concluded that when the period of the storage 
increases, the biochemical and bacteriological composition will be affected and it may have direct impact onto the life and market value of the fish.

Many studies have investigated the relation between freshness and the quality of the food product, but only a few studies focus on the relation between the freshness of the allergen extracts and their allergenicity. Determination of the quality of allergen extracts of $S$. tranquebarica allergenicity is crucial to maintain their quality for years [97], as well as to establish the expiration dating of the allergen extracts. However, no study has been conducted so far to determine the quality of allergen extracts of $S$. tranquebarica under various storage conditions.

\section{Conclusions}

Certain conformational epitopes are facilitated by food processing to be inactive and to remove the linear epitopes. Enzymatic hydrolysis was used to remove certain epitopes. Meanwhile, based on the food product quality and acceptability, the use of protein hydrolysis may lead to unwanted or unexpected changes to the food structure as well as the sensory properties. In addition, the offending agents need to foresight the presences of food allergens in trace quantities such as hidden allergen or contaminants. Therefore, it is important to have reliable and precise allergen detection methods.

\section{Acknowledgments}

This study was partially supported by UPSI 2018-0146-102-01 research grant.

\section{References}

[1] Matricardi, P. M., Kleine Tebbe, J., Hoffmann, H. J., Valenta, R., Hilger, C., Hofmaier, S., and Barber, D. 2016. "EAACI Molecular Allergology User's Guide." Pediatric Allergy and Immunology 27 (S23): 1-250.

[2] Verhoeckx, K. C., Vissers, Y. M., Baumert, J. L., Faludi, R., Feys, M., Flanagan, S., and Wichers, H. 2015. "Food Processing And Allergenicity." Food and Chemical Toxicology 80: 223-40.

[3] Pascal, M., Grishina, G., Yang, A. C., Sánchez-García, S.,
Lin, J., Towle, D., and Ayuso, R. 2015. "Molecular Diagnosis of Shrimp Allergy: Efficiency of Several Allergens to Predict Clinical Reactivity." The Journal of Allergy and Clinical Immunology: In Practice 3 (4): 521-9.

[4] Meno, K. H. 2011. "Allergen Structures and Epitopes." Allergy 66: 19-21.

[5] Ciardiello, M. A., Tamburrini, M., Liso, M., Crescenzo, R., Rafaiani, C., and Mari, A. 2013. "Food Allergen Profiling: A Big Challenge." Food Research International 54 (1): 1033-41.

[6] King, T. P., Jim, S. Y., Monsalve, R. I., Kagey-Sobotka, A., Lichtenstein, L. M., and Spangfort, M. D. 2001. "Recombinant Allergens with Reduced Allergenicity but Retaining Immunogenicity of the Natural Allergens: Hybrids of Yellow Jacket and Paper Wasp Venom Allergen Antigen 5s.” J. Immunol. 166: 6057-65.

[7] Rosmilah, M., Shahnaz, M., Zailatul, H. M., Noormalin, A., and Normilah, I. 2012. "Identification of Tropomyosin and Arginine Kinase as Major Allergens of Portunus Pelagicus (Blue Swimming Crab).” Tropical Biomedicine 29 (3): 467-78.

[8] Shriver, S. K., and Yang, W. W. 2011. "Thermal and Non-thermal Methods for Food Allergen Control." Food Engineering Reviews 3 (1): 26-43.

[9] Abdel Rahman, M., Kamath, S. D., Gagne, S., Lopata, A. L., and Helleur, R. 2013. "Comprehensive Proteomics Approach in Characterizing and Quantifying Allergenic Proteins from Northern Shrimp: Toward Better Occupational Asthma Prevention." Journal of Proteome Research 12 (2): 647-56.

[10] Liang, Y. L., Cao, M. J., Su, W. J., Zhang, L. J., Huang, Y. Y., and Liu, G. M. 2008. "Identification and Characterisation of the Major Allergen of Chinese Mitten Crab (Eriocheir sinensis)." Food Chemistry 111 (4): 998-1003.

[11] Lehrer, S. B. Ayuso, R., and Reese, G. 2003. "Seafood Allergy and Allergens: A Review." Marine Biotechnology 5 (4): 339-48.

[12] Yu, C. J., Lin, Y. F., Chiang, B. L., and Chow, L. P. 2003. "Proteomics and Immunological Analysis of a Novel Shrimp Allergen, Pen m 2." The Journal of Immunology 170 (1): 445-53.

[13] Liu, G. M., Li, B., Yu, H. L., Cao, M. J., Cai, Q. F., Lin, J. W., and Su, W. J. 2012. "Induction of Mud Crab (Scylla paramamosain) Tropomyosin and Arginine Kinase Specific Hypersensitivity in BALB/c Mice." Journal of the Science of Food and Agriculture 92 (2): 232-8.

[14] Shen, Y., Cao, M. J., Cai, Q. F., Su, W. J., Yu, H. L., Ruan, W. W., and Liu, G. M. 2011. "Purification, Cloning, Expression and Immunological Analysis of Scylla serrata Arginine Kinase, the Crab Allergen." Journal of the 
Science of Food and Agriculture 91 (7): 1326-35.

[15] Abramovitch, J. B., Kamath, S., Varese, N., Zubrinich, C., Lopata, A. L., O’Hehir, R. E., and Rolland, J. M. 2013. "IgE Reactivity of Blue Swimmer Crab (Portunus

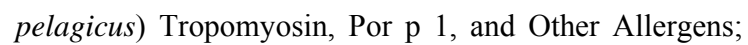
Cross-Reactivity with Black Tiger Prawn and Effects of Heating." PLoS One 8 (6): e67487.

[16] Villalta, D., Tonutti, E., Visentini, D., Bizzaro, N., Roncarolo, D., Amato, S., and Mistrello, G. 2010. "Detection of a Novel $20 \mathrm{kDa}$ Shrimp Allergen Showing Cross-Reactivity To House Dust Mites.” European Annals of Allergy and Clinical Immunology 42 (1): 20.

[17] Crespo, J. F., and Rodriguez, J. 2003. "Food Allergy in Adulthood." Allergy 58 (2): 98-113.

[18] Taylor, S. L. 2008. "Molluscan Shellfish Allergy." Advances in Food and Nutrition Research 54: 139-77.

[19] Lu, Y., Ohshima, T., Ushio, H., Hamada, Y. and Shiomi, K. 2007. "Immunological Characteristics of Monoclonal Antibodies against Shellfish Major Allergen Tropomyosin." Food Chemistry 100 (3): 1093-9.

[20] FAO. 2001. The State of World Fisheries and Aquaculture. Rome: Food and Agriculture Organization of the United Nations. p. 218.

[21] Verma, A. K., Kumar, S., Das, M., and Dwivedi, P. D. 2012. "Impact of Thermal Processing on Legume Allergens." Plant Foods for Human Nutrition 67 (4): 430-41.

[22] Chapman, M. D., Smith, A. M., Vailes, L. D., Arruda, L. K., Dhanaraj, V., and Pomés, A. 2000. "Recombinant Allergens for Diagnosis and Therapy of Allergic Disease." Journal of Allergy and Clinical Immunology 106 (3): 409-18.

[23] Besler, M., Steinhart, H., and Paschke, A. 2001. "Stability of Food Allergens and Allergenicity of Processed Foods." Journal of Chromatography B: Biomedical Sciences and Applications 756 (1-2): 207-28.

[24] Jiménez-Saiz, R., Benedé, S., Molina, E., and López-Expósito, I. 2015. "Effect of Processing Technologies on the Allergenicity of Food Products." Critical Reviews in Food Science and Nutrition 55 (13): 1902-17.

[25] Liu, G. Y., Mei, X. J., Hu, M. J., Yang, Y., Liu, M., Li, M. S., and Liu, G. M. 2018. "Analysis of the Allergenic Epitopes of Tropomyosin from Mud Crab Using Phage Display and Site-Directed Mutagenesis." Journal of Agricultural and Food Chemistry 66 (34): 9127-37.

[26] Chandan, R. C., and Kilara, A. eds. 2011. Dairy Ingredients for Food Processing. John Wiley \& Sons.

[27] Bu, G., Luo, Y., Chen, F., Liu, K., and Zhu, T. 2013. “Milk Processing as a Tool to Reduce Cow's Milk Allergenicity: A Mini-review." Dairy Science \& Technology 93 (3): 211-23.
[28] Michalski, M. C., and Januel, C. 2006. "Does Homogenization Affect the Human Health Properties of Cow's Milk?" Trends in Food Science \& Technology 17 (8): 423-37.

[29] Porter, J. W. G. 1978. "The Present Nutritional Status of Milk Proteins." International Journal of Dairy Technology 31 (4): 199-202.

[30] Taheri-Kafrani, A., Gaudin, J. C., Rabesona, H., Nioi, C., Agarwal, D., Drouet, M., and Haertle, T. 2009. "Effects of Heating and Glycation of $\beta$-Lactoglobulin on its Recognition by IgE of Sera from Cow Milk Allergy Patients." Journal of Agricultural and Food Chemistry 57 (11): 4974-82.

[31] Ehn, B. M., Ekstrand, B., Bengtsson, U., and Ahlstedt, S. 2004. "Modification of IgE Binding during Heat Processing of the Cow's Milk Allergen $\beta$-Lactoglobulin." Journal of Agricultural and Food Chemistry 52 (5): 1398-403.

[32] Bu, G., Luo, Y., Zheng, Z., and Zheng, H. 2009. "Effect of Heat Treatment on the Antigenicity of Bovine $\alpha$-Lactalbumin and $\beta$-Lactoglobulin in Whey Protein Isolate." Food and Agricultural Immunology 20 (3): 195-206.

[33] Maynard, F., Chatel, J. M., and Wal, J. M. 1999. "Immunological IgE Cross-Reactions of Bovine and Human $\alpha$-Lactalbumins in Cow's Milk Allergic Patients." Food and Agricultural Immunology 11 (2): 179-89.

[34] Escudero, C., Sánchez-García, S., Rodríguez del Río, P., Pastor-Vargas, C., García-Fernández, C., Pérez-Rangel, I., and Ibáñez, M. D. 2013. "Dehydrated Egg White: An Allergen Source for Improving Efficacy and Safety in the Diagnosis and Treatment for Egg Allergy." Pediatric Allergy and Immunology 24 (3): 263-9.

[35] Ma, X. J., Chen, H. B., Gao, J. Y., Hu, C. Q., and Li, X. 2013. "Conformation Affects the Potential Allergenicity of Ovalbumin after Heating and Glycation." Food Additives \& Contaminants: Part A 30 (10): 1684-92.

[36] Shin, I. S., Park, J. W., Shin, N. R., Jeon, C. M., Kwon, O. K., Kim, J. S., and Ahn, K. S. 2014. "Melatonin Reduces Airway Inflammation in Ovalbumin-Induced Asthma." Immunobiology 219 (12): 901-8.

[37] Mine, Y., and Zhang, J. W. 2002. "Comparative Studies on Antigenicity and Allergenicity of Native and Denatured Egg White Proteins." Journal of Agricultural and Food Chemistry 50 (9): 2679-83.

[38] Dewitt, A. M., Mattsson, L., Lauer, I., Reese, G., and Lidholm, J. 2004. "Recombinant Tropomyosin from Penaeus aztecus (rPen a 1) for Measurement of Specific Immuno-Globulin E Antibodies Relevant in Food Allergy to Crustaceans and Other Invertebrates." Molecular Nutrition \& Food Research 48 (5): 370-9.

[39] Jeebhay, M. F. 2011. "Occupational Allergy and Asthma 
in the Seafood Industry-Emerging Issues." Occupational Health Southern Africa 17 (6): 4-13.

[40] Bessot, J. C., Metz-Favre, C., Rame, J. M., De Blay, F., and Pauli, G. 2010. "Tropomyosin or Not Tropomyosin, What Is the Relevant Allergen in House Dust Mite and Snail Cross Allergies?" European Annals of Allergy and Clinical Immunology 42 (1): 3.

[41] Cartier, L. E., and Carpenter, K. E. 2014. "The Influence of Pearl Oyster Farming on Reef Fish Abundance and Diversity in Ahe, French Polynesia." Marine Pollution Bulletin 78 (1-2): 43-50.

[42] Boye, J. I. 2012. "Food Allergies in Developing and Emerging Economies: Need for Comprehensive Data on Prevalence Rates." Clinical and Translational Allergy 2 (1): 25 .

[43] Lopata, A. L., O'hehir, R. E., and Lehrer, S. B. 2010. "Shellfish Allergy." Clinical \& Experimental Allergy 40 (6): 850-8.

[44] Berg, A. H., Combs, T. P., and Scherer, P. E. 2002. "ACRP30/Adiponectin: An Adipokine Regulating Glucose And Lipid Metabolism." Trends in Endocrinology \& Metabolism 13 (2): 84-9.

[45] Zailatul Hani, M. Y., Rosmilah, M., Faizal, M., Noormalin, A., and Shahnaz, M. 2015. "Malaysian Cockle (Anadara granosa) Allergy: Identification of IgE-binding Proteins and Effects of Different Cooking Methods." Tropical Biomedicine 32 (2): 323-34.

[46] Sathe, S. K., Teuber, S. S., and Roux, K. H. 2005. "Effects of Food Processing on the Stability of Food Allergens." Biotechnology Advances 23 (6): 423-9.

[47] Vidaček, S. 2014. "Seafood.” In Food Safety Management. Academic Press, pp. 189-212.

[48] Nam, K. C., Jo, C., and Lee, M. 2010. "Meat Products and Consumption Culture in the East." Meat Science 86 (1): 95-102.

[49] Liu, G. M., Cheng, H., Nesbit, J. B., Su, W. J., Cao, M. J., and Maleki, S. J. 2010. "Effects of Boiling on the IgE-binding Properties of Tropomyosin of Shrimp (Litopenaeus vannamei).” Journal of Food Science 75 (1): $1-5$.

[50] Koizumi, D., Shirota, K., Akita, R., Oda, H., and Akiyama, H. 2014. "Development and Validation of a Lateral Flow Assay for the Detection of Crustacean Protein in Processed Foods." Food Chemistry 150: 348-52.

[51] Zailatul Hani, M. Y., Rosmilah, M., Noormalin, A., Faizal, B., and Masita. A. 2012. "Identification of the Major Allergen of Macrobrachium Rosenbergii (Giant Freshwater Prawn)." Asian Pacific Journal of Tropical Biomedicine 2 (1): 50-4.

[52] Phiriyangkul, P., Srinroch, C., Srisomsap, C., Chokchaichamnankit, D., and Punyarit, P. 2015. "Effect of Food Thermal Processing on Allergenicity Proteins in
Bombay Locust (Patanga succincta)." International Journal of Food Engineering 1 (1): 23-8.

[53] Vogelmeier, C. F., Criner, G. J., Martinez, F. J., Anzueto, A., Barnes, P. J., Bourbeau, J., and Frith, P. 2017. "Global Strategy for the Diagnosis, Management, and Prevention of Chronic Obstructive Lung Disease 2017 Report. GOLD Executive Summary." American Journal of Respiratory and Critical Care Medicine 195 (5): 557-82.

[54] Long, F., Yang, X., Wang, R., Hu, X., and Chen, F. 2015. "Effects of Combined High Pressure and Thermal Treatments on the Allergenic Potential of Shrimp (Litopenaeus vannamei) Tropomyosin in a Mouse Model of Allergy." Innovative Food Science \& Emerging Technologies 29: 119-24.

[55] Shabbir, M. A., Raza, A., Anjum, F. M., Khan, M. R., and Suleria, H. A. R. 2015. "Effect of Thermal Treatment on Meat Proteins with Special Reference to Heterocyclic Aromatic Amines (HAAs)." Critical Reviews in Food Science and Nutrition 55 (1): 82-93.

[56] Chegini, S., and Metcalfe, D. D. 2005. "Contemporary Issues in Food Allergy: Seafood Toxin-Induced Disease in the Differential Diagnosis of Allergic Reactions.” Allergy \& Asthma Proceedings 26 (3): 183-90.

[57] Cabanillas, B., Jappe, U., and Novak, N. 2018. “Allergy to Peanut, Soybean, and Other Legumes: Recent Advances in Allergen Characterization, Stability to Processing and IgE Cross-Reactivity." Molecular Nutrition \& Food Research 62 (1): 1700446

[58] Church, S. L., Grant, J. W., Ridnour, L. A., Oberley, L. W., Swanson, P. E., Meltzer, P. S., and Trent, J. M. 1993. "Increased Manganese Superoxide Dismutase Expression Suppresses the Malignant Phenotype of Human Melanoma Cells." Proceedings of the National Academy of Sciences 90 (7): 3113-7.

[59] Jones, D. A., Lelyveld, T. P., Mavrofidis, S. D., Kingman, S. W., and Miles, N. J. 2002. "Microwave Heating Applications in Environmental Engineeringa Review." Resources, Conservation and Recycling 34 (2): 75-90.

[60] Bohr, H., and Bohr, J. 2000. "Microwave-Enhanced Folding and Denaturation of Globular Proteins." Physical Review E 61 (4): 4310.

[61] Venkatachalam, M., Monaghan, E. K., Kshirsagar, H. H., Robotham, J. M., O’Donnell, S. E., Gerber, M. S., and Sathe, S. K. 2008. "Effects of Processing on Immunoreactivity of Cashew Nut (Anacardium occidentale L.) Seed Flour Proteins." Journal of Agricultural and Food Chemistry 56 (19): 8998-9005.

[62] Kaddouri, H., Nakache, S., Houzé, S., Mentré, F., and Le Bras, J. 2006. "Assessment of the Drug Susceptibility of Plasmodium falciparum Clinical Isolates from Africa by Using a Plasmodium Lactate Dehydrogenase Immunodetection Assay and An Inhibitory Maximum 
Effect Model for Precise Measurement of the 50-Percent Inhibitory Concentration." Antimicrobial Agents and Chemotherapy 50 (10): 3343-9.

[63] Izquierdo, F. J., Peñas, E., Baeza, M. L., and Gomez, R. 2008. "Effects of Combined Microwave and Enzymatic Treatments on the Hydrolysis and Immunoreactivity of Dairy Whey Proteins." International Dairy Journal 18 (9): 918-22.

[64] Leszczynska, J., Łącka, A., Szemraj, J., Lukamowicz, J., and Zegota, H. 2003. "The Effect of Microwave Treatment on the Immunoreactivity of Gliadin and Wheat Flour." European Food Research and Technology 217 (5): 387-91.

[65] Peleg, M. 1999. "On Calculating Sterility in Thermal and Non-thermal Preservation Methods." Food Research International 32 (4) 271-8.

[66] Lindh, U. 2013. "Biological Functions of the Elements." In Essentials of Medical Geology. pp. 129-77.

[67] Rodrigues, S. A., Wade, K. R., Thambyah, A., and Broom, N. D. 2012. "Micromechanics of Annulusend Plate Integration in the Intervertebral Disc." The Spine Journal 12 (2): 143-50.

[68] Shahidi, F., and Botta, J. R. 1994. "Seafood Processing By-Products." In Seafoods: Chemistry, Processing Technology and Quality. Boston, MA: Springer, pp. 320-34.

[69] Tahergorabi, R., Beamer, S. K., Matak, K. E., and Jaczynski, J. 2011. "Salt Substitution in Surimi Seafood and Its Effects on Instrumental Quality Attributes." LWT-Food Science and Technology 48 (2) 175-81.

[70] Sampson, H. A., Mu noz-Furlong, A., Bock, S. A., Schmitt, C., Bass, R., Chowdhury, B. A., et al. "Symposium on the Definition and Management of Anaphylaxis: Summary Report." J Allergy Clin Immunol 115: 584-91.

[71] Deng, Y., Luo, Y., Wang, Y., and Zhao, Y. 2015. "Effect of Different Drying Methods on the Myosin Structure, Amino Acid Composition, Protein Digestibility and Volatile Profile of Squid Fillets.” Food Chemistry 171: 168-76.

[72] Martínez-Alvarez O., and Gómez-Guillén, M. C. 2005. "The Effect of Brine Composition and $\mathrm{pH}$ on the Yield and Nature of Water-Soluble Proteins Extractable from Brined Muscle of Cod (Gadus morhua)." Food Chem 92: 71-7.

[73] Zheng, H., and Lu, H. 2011. "Effect of Microwave Pretreatment on the Kinetics of Ascorbic Acid Degradation and Peroxidase Inactivation in Different Parts of Green Asparagus (Asparagus officinalis L.) during Water Blanching." Food Chemistry 128 (4): 1087-93.

[74] Burgaard, M.G. and Jorgensen, B.M. (2010). Effect of temperature on quality-related changes in cod (Gadus morhua) during short- and long-term frozen storage.
Journal of Aquatic Food Product Technology, 19, 249-263.Bessot, J. C., Metz-Favre, C., Rame, J. M., De Blay, F., and Pauli, G. 2010. "Tropomyosin or Not Tropomyosin, What is the Relevant Allergen in House Dust Mite and Snail Cross Allergies?" European Annals of Allergy and Clinical Immunology 42 (1): 3.

[75] Suzuki, M., Kobayashi, Y., Hiraki, Y., Nakata, H., and Shiomi, K. 2011. "Paramyosin of the Disc Abalone Haliotis Discus: Identification as a New Allergen and Cross-Reactivity with Tropomyosin." Food Chemistry 124 (3): 921-6.

[76] Beyer, K., Morrowa, E., Li, X. M., Bardina, L., Bannon, G. A., Burks, A. W., and Sampson, H. A. 2001. "Effects of Cooking Methods on Peanut Allergenicity." Journal of Allergy and Clinical Immunology 107 (6): 1077-81.

[77] Lasekan, A., Cao, H., Maleki, S., and Nayak, B. 2017. "Shrimp Tropomyosin Retains Antibody Reactivity after Exposure to Acidic Condition." Journal of the Science of Food and Agriculture 97 (11): 3623-30.

[78] Houston, N. L., Lee, D. G., Stevenson, S. E., Ladics, G. S., Bannon, G. A., McClain, S., Privalle, L., Stagg, N., Herouet-Guicheney, C., MacIntosh, S. C., and Thelen, J. J. 2011. "Quantitation of Soybean Allergens Using Tandem Mass Spectrometry." Journal of Proteome Research 10 (2): 763-73.

[79] Huang, Y. Y., Liu, G. M., Cai, Q. F., Weng, W. Y., Maleki, S. J., Su, W. J., and Cao, M. J. 2010. "Stability of Major Allergen Tropomyosin and Other Food Proteins of Mud Crab (Scylla serrata) by in vitro Gastrointestinal Digestion." Food and Chemical Toxicology 48 (5): 1196-201.

[80] Schmidt, M. D., Schmidt, M. S., Butelman, E. R., Harding, W. W., Tidgewell, K., Murry, D. J., and Prisinzano, T. E. 2005. "Pharmacokinetics of the Plant-Derived $\kappa$-Opioid Hallucinogen Salvinorin A in Nonhuman Primates." Synapse 58 (3): 208-10.

[81] Untersmayr, E., and Jensen-Jarolim, E. 2008. "The Role of Protein Digestibility and Antacids on Food Allergy Outcomes." Journal of Allergy and Clinical Immunology 121 (6): 1301-8.

[82] Kim, S. F., Huang, A. S., Snowman, A. M., Teuscher, C., and Snyder, S. H., 2007. "Antipsychotic Drug-Induced Weight Gain Mediated by Histamine H1 Receptorlinked Activation of Hypothalamic AMP-Kinase." Proceedings of the National Academy of Sciences 104: 3456-9.

[83] Yagami, T., Haishima, Y., Nakamura, A., Osuna, H., and Ikezawa, Z. 2000. "Digestibility of Allergens Extracted from Natural Rubber Latex and Vegetable Foods." Journal of Allergy and Clinical Immunology 106 (4): 752-62.

[84] Yu, H. L., Cao, M. J., Cai, Q. F., Weng, W. Y., Su, W. J., and Liu, G. M. 2011. "Effects of different processing 
methods on digestibility of Scylla paramamosain allergen (tropomyosin)." Food and Chemical Toxicology 49 (4): 791-8.

[85] Chen, H. L., Cao, M. J., Cai, Q. F., Su, W. J., Mao, H. Y., and Liu, G. M. 2013. "Purification and Characterisation of Sarcoplasmic Calcium-Binding Protein, a Novel Allergen of Red Swamp Crayfish (Procambarus clarkii)." Food chemistry 139 (1-4): 213-23.

[86] Lee, B. J., and Park, H. S. 2004. "Common Whelk (Buccinum undatum) Allergy: Identification of IgE-Binding Components and Effects of Heating and Digestive Enzymes." Journal of Korean Medical Science 19 (6): 793-9.

[87] Villamie, M., Jong, P., 2000. "Influence of High-Intensity Ultrasound and Heat Treatment in Continuous Flow on Fat Proteins, and Native Enzymes of Milk." J. Agric. Food. Chem. 48 (2): 472-8.

[88] Li, Z. X., Lin, H., Cao, L. M., and Jameel, K. 2006. "Effect of High Intensity Ultrasound on the Allergenicity of Shrimp." Journal of Zhejiang University Science $B 7$ (4): 251-6.

[89] Chun, H. N., Kim, B., and Shin, H. S. 2014. "Evaluation of a Freshness Indicator for Quality of Fish Products during Storage." Food Science and Biotechnology 23 (5): 1719-25.
[90] Sotelo, A., Hernandez, M., Montalvo, I., and Sousa, V. 1994. "Amino Acid Content and Protein Biological Evaluation of 12 Mexican Varieties of Rice." Cereal Chemistry 71 (6): 605-9.

[91] Chebet, L. 2010. "'Rapid' (Alternative) Methods for Evaluation of Fish Freshness and Quality." Doctoral dissertation.

[92] Leelapongwattana, K., Benjakul, S., Visessanguan, W., and Howell, N. K. 2005. "Physicochemical and Biochemical Changes during Frozen Storage of Minced Flesh of Lizardfish (Saurida micropectoralis).” Food Chemistry 90 (1-2): 141-50.

[93] Burgaard, M. G., and Jorgensen, B. M. 2011. "Effect of Frozen Storage Temperature on Quality-Related Changes in Rainbow Trout (Oncorhynchus mykiss)." Journal of Aquatic Food Product Technology 20 (1): 53-63.

[94] Singh, R. P., and Wang, C. Y. 1977. "Quality of Frozen Foods a Review." Journal of Food Process Engineering 1 (2): 97-127.

[95] Gandotra, R., Sharma, S., Koul, M., and Gupta, S. 2012. "Effect of Chilling and Freezing on Fish Muscle." Journal of Pharmacy and Biological Sciences 2 (5): 5-9.

[96] Plunkett, G. 2016. "Update: Stability of Allergen Extracts to Establish Expiration Dating." Current Opinion in Otolaryngology \& Head and Neck Surgery 24 (3): 261-9. 